\title{
Relações Executivo-Legislativo no novo constitucionalismo latino-americano: o hiperpresidencialismo no Equador
}

\section{Guilherme Andrade Silveira ${ }^{1}$}

1 Mestrando em Ciência Política (DCP/UFMG), Brasil. E-mail: guilherme1313@gmail.com

\begin{abstract}
RESUMO: Embora a nova Constituição do Equador de 2008 ofereça caminhos e possibilidades para a construção de um novo modelo democrático, mais avançado em termos de participação política e controle do Estado pela população, ela também está carregada de limites e contradições, notadamente relacionados à concentração de poderes pelo presidente. Esse trabalho investiga o paradoxo existente entre o hiperpresidencialismo e a ampliação dos mecanismos de participação popular. Para tanto, analisa a distribuição formal de poderes, com foco na relação Executivo-Legislativo, bem como identifica os seus principais resultados políticos. Como efeito desse paradoxo, o artigo conclui que a institucionalidade de um sistema político que não se constrói sobre o princípio da autonomia e do equilíbrio entre as funções do Estado pode debilitar sua própria institucionalidade democrática. Quando o Presidente dispõe de uma posição privilegiada frente às demais funções do Estado e à cidadania, cria-se as condições para o abuso do Executivo e para limitar o acesso da população ao Estado.
\end{abstract}

Palavras-chave: Hiperpresidencialismo; Equador; Novo Constitucionalismo LatinoAmericano

\section{INTRODUÇÃO}

Desde o final do século passado e, sobretudo, nos primeiros anos do século XXI, a América Latina assistiu a um importante processo de mudanças políticas, sociais, econômicas e culturais, protagonizado pela própria população, especialmente, pelos grupos tradicionalmente excluídos e marginalizados em todas essas dimensões, como os povos originários, que culminaram na positivação de novos e antigos direitos, por meio de processos constituintes amplamente democráticos. Como resultado, as Constituições da Colômbia (1991), Venezuela (1999), Equador (2008) e Bolívia (2009) ${ }^{1}$ estão sendo analisadas como a construção de um arcabouço jurídico inovador e diferenciado, formando o que vem sendo chamado pelos estudiosos de "Novo Constitucionalismo Latino-Americano"² (SANTOS,

\footnotetext{
${ }^{1}$ Reconhecemos a existência de um importante debate acerca da inclusão dos casos da Colômbia e da Venezuela no paradigma do Novo Constitucionalismo Latino-Americano. Nos parece ser adequado o enquadramento que caracteriza as constituições desses dois países como percussora desse movimento, apresentando, no entanto, limitações profundas frente aos avançados representados pelos casos equatoriano e boliviano. Contudo, entendemos que esse debate deva ser feito de maneira robusta, algo que ultrapassaria os objetivos deste estudo, que analisa apenas os dois últimos casos, por serem os únicos em que o Estado foi concebido, em seu projeto constitucional, como plurinacional.

${ }^{2}$ Esse movimento tem recebido variadas denominações. Uma listagem bastante completa pode ser encontrada em
} 
2009, MAGALHÃES, WEIL, 2010; VICIANO PASTOR, MARTÍNEZ DALMAU, 2010 e 2011; GARAVITO, 2011; LINZÁN, FRANCO, 2011; GARGARELLA, 2010).

Diante da falta de habilidade do "velho" constitucionalismo para resolver os problemas fundamentais da sociedade, o Novo Constitucionalismo se distancia e representa uma ruptura em relação aos modelos prévios, sendo marcado pela participação popular, mais ou menos limitada dependendo do caso, durante o processo de elaboração e aprovação das cartas magnas. Entre as principais características desse paradigma constitucional estão a ativação direta do poder constituinte pelo povo, a ampliação de mecanismos de participação política e de formas de controle do Estado pela população, uma extensa carta de direitos e garantias, a integração de setores sociais historicamente marginalizados, especialmente os povos indígenas, a rigidez ${ }^{3}$ e a forte normatividade constitucional, bem como a definição de um papel mais ativo do Estado na economia, associado ao maior compromisso com a integração regional.

Dentro do marco do Novo Constitucionalismo Latino-Americano, as novas constituições do Equador, de 2008, e da Bolívia, de 2009, representam casos emblemáticos das transformações vivenciadas na região durante as últimas décadas. Além de contar com as características apresentadas anteriormente, essas constituições têm despertado grande interesse devido às importantes inovações apresentadas, sejam em termos institucionais, como a redefinição das funções do Estado, seja em termos de direitos, como participativos e buen vivir. De forma mais destacada, essas constituições propõem uma refundação do próprio conceito de Estado, em substituição ao modelo de Estado-nação, cunhado pela tradição liberal europeia, tipicamente excludente e homogeneizador, pelo modelo de Estado Plurinacional, em ruptura aos processos de colonização e a partir do reconhecimento dos povos indígenas, campesinos e originários.

Contudo, embora as novas experiências constitucionais na América Latina nos ofereçam caminhos e possibilidades para a construção de um novo modelo democrático, mais avançado em termos de participação política e controle do Estado pela população, elas também estão carregadas de limites e contradições, que colocam em risco as próprias conquistas do poder constituinte nesses países. Nesse sentido, ao analisar os textos constitucionais promulgados no marco do Novo Constitucionalismo Latino-Americano, diversos autores têm argumentado acerca da manutenção de um modelo de organização dos poderes políticos comumente associado, de forma generalizada, ao contexto da região: o "hiperpresidencialismo". A condição paradoxal dessas constituições reside no fato de elas terem surgido apoiadas em uma perspectiva contrária à um sistema de concentração de poderes nas mãos do presidente, sendo caracterizadas por um extenso rol de direitos e pela ampliação dos mecanismos de participação política e controle do Estado pela população, propondo um novo lugar à relação entre soberania e poder constituído, com forte ênfase em sua legitimidade.

Brandão (2015).

3 "La rigidez constitucional, entendida como se ha definido anteriormente, no busca la perdurabilidad de la constitución, sino la modificación de ésta exclusivamente por el poder constituyente, esto es, el originario" (VICIANO PASTOR; MARTíNEZ DALMAU, 2011, p. 18). 
Essa tendência mais geral do constitucionalismo contemporâneo da região tem sido observada de forma mais contundente no caso equatoriano. Em termos de inovação democrática, sua nova Constituição garante importante espaço à participação política, apresentando formas de democracia direta, com a possiblidade de criação, reforma ou revogação de normas legais; previsão de audiências públicas, assembleias, conselhos populares e consultivos, observatórios e mecanismos de investigação e controle da administração pública; bem como formas de representação nos processos legislativos e nas seções dos governos autônomos. Além disso, uma das mais destacadas inovações dessa Constituição está na definição de uma quarta função do Estado, a de Transparência e Controle Social ${ }^{4}$, que propõe um novo status e locus para a participação, que passa agora a atuar de dentro do próprio aparelho do Estado.

Por sua vez, a Constituição equatoriana também apresenta mecanismos de concentração do poder nas mãos do chefe da Função Executiva, entre os quais estão os de iniciativa legislativa, inclusive com a possiblidade de trâmite em regime de urgência com promulgação automática em forma de decreto-lei quando não analisado pela Assembleia Nacional; iniciativa exclusiva em matérias que aumentem, modifiquem ou suprimam impostos, aumentem o gasto público ou modifiquem a divisão político administrativa do País; poderes de veto; elaboração do Orçamento Geral do Estado; e convocação extraordinária da Assembleia Nacional, com controle de sua agenda. Além disso, algumas modificações constitucionais realizadas após a promulgação da Constituição garantiram ao Presidente a preponderância na indicação dos membros do Conselho de Magistratura e do Conselho de Participação Cidadã e Controle Social, instituições pertencentes a outras funções do Estado, que possuem grande importância dentro do ordenamento Constitucional.

Dessa forma, esse trabalho pretende aprofundar a investigação acerca do aparente paradoxo existente entre o hiperpresidencialismo e a ampliação dos mecanismos de participação política e controle do Estado pela população, promovidos dentro do paradigma do Novo Constitucionalismo Latino-Americano. Dessa forma, buscará analisar a distribuição formal de poderes no marco da Constituição equatoriana, como foco na relação entre o Executivo e o Legislativo, bem como identificar os principais resultados políticos relacionados a essa forma de organização do poder sobre a produção de políticas públicas e o desempenho do governo, tendo em vista o desenho das instituições políticas.

\section{DISTRIBUIÇÃO DE PODERES E CONTROLE DA AGENDA POLÍTICA}

Durante vários anos, os estudos sobre os governos concentraram sua atenção na comparação entre os sistemas presidencialista e parlamentarista. Esses trabalhos estiveram orientados por análises macro institucionais, de caráter normativo, que acentuavam os efeitos de diferentes engenharias institucionais sobre o processo decisório, os resultados

${ }^{4}$ A Função de Transparência e Controle Social é formada pelas seguintes instituições: Conselho de Participação Cidadã e Controle Social, a Defensoria do Povo, a Controladoria Geral do Estado e superintendências (organismos técnicos de vigilância, auditoria, intervenção e controle das atividades e dos serviços prestados por entidades públicas e privadas). 
políticos e a estabilidade democrática. As estruturas formais conformariam, nesse sentido, o arranjo em que se representariam os vários interesses dos atores políticos, com consequências extremamente diferentes entre elas, levando os atores a uma inevitável "política de escolha estrutural" (MOE, 1990). O resultado dessa escolha delineia uma forma institucional de democracia que possui a sua própria dinâmica política, funcionando como um código genético que programa os tipos de burocracias, as estruturas de liderança, os arranjos de pessoal e outras propriedades que compõem os governos (MOE; CALDWELL, 1994).

Nesse campo de estudos, uma das teses de maior repercussão no contexto latinoamericano foi aquela formulada por Linz (1994), segundo a qual a democracia não seria compatível com o presidencialismo, já que este teria menor probabilidade de proporcionar a estabilidade dos regimes do que o parlamentarismo ${ }^{5}$. A crítica do autor baseava na própria estrutura de accountability e na rigidez desse sistema, que dificultaria a formação de consensos e estimularia o surgimento de partidos fracos e governos mais personalistas e fragmentados. O desenvolvimento da literatura após as descobertas de Linz, no entanto, trouxe novas perspectivas para o debate acerca do presidencialismo, demonstrando a possibilidade de se estabelecer governos democráticos estáveis dentro desse regime. Ao contrário das previsões desse autor, a introdução de determinadas instituições ao presidencialismo tornava possível a governabilidade do presidente, inclusive fazendo com que ele se assemelhasse à lógica de funcionamento do parlamentarismo, como argumentado por Colomer e Negretto (2005) acerca do presidencialismo de coalizão latino-americano.

A partir de então, o debate que se estabeleceu nessa literatura esteve focado não mais na sobrevivência da democracia, mas sim nos efeitos de determinadas instituições e mecanismos nos diferentes sistemas de governo. Nessa agenda, a existência de um trade-off entre governabilidade e accountability tem merecido destaque na comparação de arranjos institucionais (CAREY, 2014). Para Lijphart (2008), esse dilema coloca a escolha estrutural dos atores entre dois polos: o modelo majoritário, em que há o predomínio do Poder Executivo, e o modelo consensual, caracterizado por relações mais equilibradas entre os poderes Executivo e Legislativo. Entre eles, haveria uma variedade de formas em que se organizaria o poder em uma democracia, indo do completo equilíbrio ao sério desequilíbrio, em que cada sistema teria suas próprias vantagens e desvantagens. Segundo essa análise, o sistema presidencialista teria, simultaneamente, duas fontes de legitimidade do poder, a do Executivo e do Legislativo, favorecendo a existência de mecanismos de "checks and balances" e uma maior responsividade do governo, mais democrático, porque o Executivo é eleito diretamente, mais estável, por que possui um mandato fixo, e mais protetivo dos interesses das minorias, porque seu poder é mais limitado (LIJPHART, 2008; MOE; CALD-

\footnotetext{
${ }^{5}$ Mainwaring e Shugart (1993) sintetizam o argumento de Linz em quatro pontos: (1) no presidencialismo, o presidente e a assembleia têm reivindicações concorrentes à legitimidade, dificultando a resolução de disputas de interesses entre esses atores; (2) o mandato fixo do presidente introduz uma rigidez que é menos favorável à democracia do que a flexibilidade oferecida pelos sistemas parlamentaristas, já que os governos são eleitos para um período de governo fixo; (3) o presidencialismo tem uma lógica do tipo "o vencedor leva tudo" que é desfavorável à estabilidade democrática; e (4) o "estilo presidencialista de política" é menos propício à democracia do que o estilo parlamentarista, levando-os a serem, ao mesmo tempo, chefes de Governo e de Estado, papéis que, por vezes, podem entrar em conflito.
} 
WELL, 1994).

Chaisty, Cheeseman e Power (2014), por sua vez, analisam a construção de coalizões legislativas pelo presidente na América Latina, na África Subsaariana e nos países da antiga União Soviética, demonstrando que os presidentes utilizam de um conjunto de ferramentas, ou como os autores denominam, do "Executive Toolbox", para ampliar a sua governabilidade. Segundo os autores, mesmo comportando-se de forma assemelhada ao parlamentarismo, o presidencialismo de coalizão ainda apresenta distinções significativas em relação ao primeiro sistema e, portanto, os presidentes necessitam utilizar de ferramentas institucionais formais e informais para facilitar o processamento de seus interesses nesse arranjo. Esse conjunto é formado por cinco ferramentas - poder de agenda, prerrogativas orçamentárias, administração de gabinetes, poderes partidários e instituições informais às quais os atores recorrem, tipicamente, a mais de uma delas ao mesmo tempo ("presidential toolkit").

Os estudos sobre os sistemas de governo, a partir dessa lógica, passaram a reconhecer a existência não de um sistema parlamentarista e outro presidencialista, mas sim de parlamentarismos e presidencialismos (SHUGART; CAREY, 1992). Em relação a esses últimos, Shugart e Carey (1992) destingem três tipos de sistemas presidenciais: o presidencialismo puro, tendo como exemplo típico os Estados Unidos; o sistema premier-presidential ou semipresidencialismo, cujo presidente eleito por voto popular tem seu gabinete sujeito à confiança do parlamento, como pode ser classificado o caso da França; e o sistema president-parliamentary, no qual o presidente popularmente eleito tem o poder de nomear e destituir seu gabinete, pode dissolver o parlamento e/ou legislar, sendo exemplos dessa categoria o Peru (Constituição de 1968) e o Equador (Constituição de 1962).

Para esses autores, as críticas realizadas por Linz se aplicariam somente às presidências com amplos poderes legislativos, em que os conflitos teriam menor espaço para serem ajustados, já que presidentes teriam maiores incentivos para agir unilateralmente, sem negociar com o Legislativo ${ }^{6}$. Tal situação levaria a um quadro mais conflituoso, tendo em vista a suposição de que os poderes do presidente são utilizados contra a maioria parlamentar, tendo em vista que são poderes constitucionais. Shugart e Carey (1992) argumentam ainda que, em contextos de presidentes fracos, as lideranças partidárias possuem maiores incentivos para exercer controle sobre os membros de seus partidos, gerando, assim, partidos mais programáticos. Para eles, o "segredo da ineficiência" é, pois, a combinação de presidência forte com partidos fracos.

Cox e Morgenstern (2002) também elaboraram uma tipologia do presidencialismo latino-americano, tendo em vista a participação direta do presidente no processo legislativo. Essa tipologia leva em consideração o nível de apoio que o Poder Executivo tem no Legislativo, bem como as estratégias dos presidentes e as "reações" dos parlamentares. São quatro classificações: (1) presidente imperial-Legislativo recalcitrante; (2) presidente nacio-

${ }^{6}$ Por outro lado, "o presidencialismo com Congresso forte contém um princípio democrático para a resolução de conflitos entre poderes: o princípio de que a assembleia prevalece, sujeita a um compromisso com o presidente" (SHUGART; CAREY, 1992, p. 165). 
nalmente orientado-Legislativo paroquial; (3) presidente de coalizão-Legislativo viável; e (4) presidente dominante-Legislativo subserviente. Os governos de tipo 1 e 4 são os que mais nos interessam neste trabalho ${ }^{7}$. O primeiro tipo é formado por governos minoritários, que enfrentam maiorias hostis no parlamento, adotando estratégias de ação unilateral a partir de seus poderes constitucionais. Já os governos de tipo 4 são formados por presidentes dominantes, que ditam as regras e as políticas frente a parlamentos subservientes.

As obras de Shugart e Carey (1992) e de Cox e Morgenstern (2002) sugerem que os poderes de agenda de que o presidente dispõe, ao invés de reforçar padrões conflitivos de relação entre o Executivo e o Legislativo, podem facilitar a coordenação dos parlamentares pelo presidente, mesmo aqueles que contam com maioria no parlamento, especialmente em governos de coalizão. A partir desses estudos, uma série de autores passaram a analisar a influência do presidente sobre a agenda pública, especialmente na produção legislativa do parlamento. Ao passar de uma abordagem "pessoal", que vê o presidente como um indivíduo cujas habilidades, personalidades e experiências moldam o seu sucesso no gabinete $^{8}$, incrementaram-se os estudos que focavam no fortalecimento institucional da presidência. Para esses autores, a característica da moderna presidência é a sua capacidade para tomar ações unilateralmente. Muitos desses estudos se interessaram no uso de vetos e nos poderes de agenda-setting para explicar diferentes dinâmicas e performances do Executivo.

Na América Latina, diversos autores argumentam que os presidentes são os atores políticos mais fortes, por contarem com um amplo leque de poderes para aumentar a sua governabilidade, tais como poderes de veto e decreto com força de lei (e.g., SAIEGH, 2009). Além disso, o caso da região se diferencia dos demais, sobretudo do caso clássico estadunidense, devido à composição dos governos, geralmente fragmentados em coalizões multipartidárias. As análises realizadas sobre esse aspecto jogam luz sobre o "toolbox" utilizado pelos presidentes para construir suas maiorias legislativas (RAILE; PEREIRA; POWER, 2011), seja por meio de poderes de agenda, pork, nomeações ministeriais ou o desenho da presidência institucional (FIGUEIREDO; LIMONGI, 1999; AMORIM NETO, 2000; ALTMAN, 2000; MARTINEZ GALLARDO, 2012; INÁCIO; LLANOS, 2014).

Existe, ainda, uma forte literatura focada no processo de formulação legislativa do presidente, centrada nas condições em que esse ator utiliza de meios ordinários (estatutários) e extraordinários (não-estatutários) para desenvolver iniciativas de lei (AMORIM NETO; COX; MCCUBBINS 2003; NEGRETTO, 2004; PEREIRA; POWER; RENNÓ, 2005). Para Cox e McCubbins (2005, p. 9), por exemplo, os poderes de agenda são cartelizados, isto é, "even though voting power in democratic legislatures is everywhere equal, proposal and veto

\footnotetext{
7 "Os dois tipos intermediários ( 2 e 3 ) referem-se a presidentes que contam com apoio médio no Legislativo e, por essa razão, procuram negociar o curso das políticas. $O$ que diferencia esses dois tipos são as moedas de troca utilizadas na barganha pelo apoio parlamentar: benefícios particularistas (patronagem e pork) posições ministeriais; concessões sobre políticas e poderes de agenda" (FIGUEIREDO, 2008, p.14).

${ }^{8}$ Essa abordagem, focada nas qualidades pessoais do ocupante do gabinete - em suas habilidades, temperamento e experiência, pode ser exemplificada pela frase de Richard Neustadt (1960), segundo a qual "presidencial power is the power to persuade".
} 
power are everywhere unequal ${ }^{\prime \prime}$. Para os autores, em relação aos poderes de agenda, haveria um trade-off entre o aumento do poder de veto, e, com isso, maiores custos de negociação, e o aumento do poder de realizar propostas, gerando maiores externalidades decorrentes das decisões realizadas.

Nesse sentido, são promissores os estudos que analisam o poder de agenda a partir de uma perspectiva relacional, buscando problematizar a distribuição de poderes entre o Legislativo e o Executivo. Saiegh (2009) sugere que o sucesso legislativo do presidente é originado tanto de seu poder de agenda quanto do controle de uma maioria legislativa, seja por meio do apoio partidário disciplinado ou de uma coalizão majoritária. O autor argumenta "that uncertainty about legislators' voting behavior is the key factor that shapes the capacity of chief executives to successfully enact policy changes through acts of government that carry the force of law by winning legislative majorities" (SAIEGH, 2009, p. 1344). Segundo ele, a compreensão da relação entre o Executivo e o Legislativo deve considerar a existência de informações incompletas como parte da análise, tendo em vista, inclusive, que as taxas de aprovação legislativa dos presidentes podem variar muito entre países e, mesmo, ao longo do tempo em cada um deles.

Da mesma forma, Diermeier e Vlaicu (2009) argumentam que diferenças nas taxas de sucesso legislativa ${ }^{10}$ do presidente decorrem de diferenças no nível de incerteza que o chefe do Executivo possui em relação aos legisladores e não de seu poder. Por sua vez, outros autores enfatizam o papel dos partidos, seja estruturando o processo legislativo, por meio do controle da agenda no parlamento e da organização de seus legisladores (e.g., COX; MCCUBBINS, 2005; ROHDE, 2013), ou na obtenção de cargos e recursos (e.g., JENKINS e MONROE, 2012). Por fim, Moe e Howell (1999) demonstram como o uso das prerrogativas são aceitos pelo Poder Legislativo e Judiciário devido a razões enraizadas na natureza dessas instituições ${ }^{11}$. Em outras palavras, essa literatura sustenta que Executivo e Legislativo possuem preferências e estratégias diferentes, e que, portanto, faz-se necessário analisar os incentivos institucionais existentes para que ambos os poderes possam colaborar entre si.

9 "The agenda is cartelized when: (1) special agenda-setting powers are formally delegated to various offices, such as committee chairs, the speakership, and the Rules Committee; (2) the majority party's members secure most of these offices, so that "agenda-setting services" can be procured only from members of the procedural cartel, just as certain kinds of economic services or goods can be procured only from the relevant economic cartel; and (3) the majority party's "senior partners," who hold these agenda-setting offices, act according to a minimal fiduciary standard namely, that they do not use their official powers to push legislation that would pass on the floor against the wishes of most in their party" (COX; MCCUBBINS, 2005, p. 9).

${ }^{10}$ Segundo eles, "a legislative success rate is the frequency with which bills proposed or endorsed by the executive government are passed by the legislature in a given legislative session" (DIERMEIER; VLAICU, 2009, p. 2).

${ }^{11}$ Analisando o caso estadunidense, os autores argumentam que os poderes presidenciais para ação unilateral constituem uma forca na política estadunidense porque eles não estão especificados na Constituição. Em contraste aos poderes de veto, nomeação, por exemplo, eles derivam sua força e resiliência da ambiguidade do contrato. Eles também argumentam que os presidentes possuem incentivos para pressionar essa ambiguidade implacavelmente, estrategicamente e com moderação, para expandir os seus poderes, e que nem o Congresso nem a corte são propensas a pará-lo. O congresso, devido aos problemas de ação coletiva torná-lo ineficaz e sujeito à manipulação. Já a Suprema Corte é capaz de tomar medidas contra os presidentes, mas é improvável que o façam a maior parte do tempo, e de fato possui incentivos para ser simpática (MOE; HOWELL, 1999).

PRACS: Revista Eletrônica de Humanidades do Curso de Ciências Sociais da UNIFAP

https://periodicos.unifap.br/index.php/pracs ISSN 1984-4352 Macapá, v. 11, n. 2, p. 211-228, jul./dez. 2018 


\section{O HIPERPRESIDENCIALISMO NO EQUADOR}

Entre 1978 e 2009, todos os países da América Latina substituíram ou reformaram suas constituições. Conforme apresenta Gabriel Negretto (2009), pode-se distinguir três motivações básicas para a ocorrência dessas transformações: (1) modificações no regime político, como a caída dos regimes ditatoriais que marcaram a região durante o século XX; (2) crises políticas, que tornam inviável a manutenção das instituições vigentes; e (3) modificações nas preferências ou distribuição de poder entre os principais atores políticos. Somente o Equador, durante essas três décadas, promulgou três novas constituições nacionais: em 1978, 1998 e 2008. Essas reformas correspondem, em maior ou menor medida, a cada uma das três causas apresentadas, sendo que os eventos que as motivaram possuem grandes implicações sobre o conteúdo das constituições.

Julio Echeverría (2005), ao analisar os paradigmas do presidencialismo no Equador, defende que o reforço do regime presidencial é resultado das condições políticas experimentas pelo país durante as últimas décadas. Na Carta Magna de 1978, o Equador experimentava a abertura democrática após o regime militar instaurado seis anos antes, como reação ao quinto governo de José María Velasco Ibarra. Nesse período, o presidencialismo forte, que havia sido historicamente associado à instabilidade democrática na América Latina ${ }^{12}$, passa a ser defendido como forma de garantir e facilitar a implementação de programas neoliberais, fundamentados em políticas monetaristas, anti-estatistas e com drástica redução dos gastos públicos (GARGARELLA, 2010). De forma adicional, no caso do Equador, a disputa entre presidente e parlamentares de centro-esquerda quanto a políticas econômicas e redistributivas geraram forte enfrentamento entre o Executivo e o Legislativo e uma profunda crise de governabilidade durante os anos de 1980 e grande parte dos anos 90 (ECHEVERRÍA, 2005). A saída por um presidencialismo forte, capaz de contornar as travas políticas entre os dois poderes foi, então, adotada pela Assembleia Constituinte do País em 1998.

O primeiro governo posterior à promulgação dessa Constituição, presidido por Jamil Mahuad, levou o país a sua pior crise econômica, gerando uma nova espiral de conflitos (RAMÍREZ GALLEGOS, 2010). O período que se estende entre 2000 e 2005 foi de intensa mobilização social e instabilidade política, que culminou com a caída de três presidentes ${ }^{13}$. Esse movimento de contestação permitiu a emergência de Rafael Correa como opção política, eleito em $2006^{14}$. Em abril de 2007, Correa realizou uma consulta popular sobre a convocação de uma nova Assembleia Nacional Constituinte, que alcançou $80 \%$ de aprova-

\footnotetext{
${ }^{12}$ Esse argumento pode ser visto em Nino (1987) e Linz e Valenzuela (1994). A partir dos anos de 1980, a correlação entre hiperpresidencialismo e instabilidade perde a centralidade a partir de estudos como os de Cheibub e Limongi (2002) e O'Donnell (1991), entre outros.

${ }^{13}$ Jamil Mahuad (1998-2000), Gustavo Noboa (2000-2003) e Lucio Edwin Gutiérrez Borbúa (2003-2005).

${ }^{14}$ Rafael Correa havia sido Ministro de Economia e Finanças no início do Governo de Alfredo Palacio, que assumiu o cargo interinamente entre 2005 e 2007, propondo uma economia fortemente nacionalista, em detrimento da ortodoxia neoliberal e das orientações do Banco Mundial e do FMI. Correa renunciou ao cargo por discordar da política presidencial e, em 2006, foi eleito presidente pelo Alianza PAIS (Patria Altiva y Soberana), organização que ele mesmo criou.
} 
ção. A ampla participação da população e dos movimentos e organizações sociais são destacadas por diversos autores ${ }^{15}$, demonstrando a amplitude desse processo constituinte "desde abajo". Entretanto, a intervenção presidencial durante a elaboração da Carta Magna equatoriana também foi uma das marcas desse processo, o que acabou gerando grandes conflitos ${ }^{16}$.

Conforme assinalamos, a nova Constituição equatoriana, aprovada em 28 de setembro de 2008 em referendo popular, apresentou uma estrutura bastante complexa, marcada pelo fortalecimento dos direitos sociais e de participação política, bem como pela ampliação dos poderes presidenciais. Diante desse cenário, não é possível analisar essas transformações, como se tratassem de duas partes autônomas da Constituição, ou seja, como se uma não influenciasse o resultado obtido a partir da outra (GARGARELLA, 2010). Oyarte Martínez (2009) defende que a nova Constituição não só não reduz as faculdades presidenciais consagrados na Carta de 1998, como as aumenta, e de forma correlata, diminui os poderes da Função Legislativa.

Quadro 1. Componentes individuais do Índice de Poderes Presidenciais* nas Constituições do Equador

\begin{tabular}{|c|c|c|c|c|}
\hline \multicolumn{2}{|c|}{ Componentes Individuais } & Constituição de 1978 & Constituição de 1998 & Constituição de 2008 \\
\hline \multirow{6}{*}{ 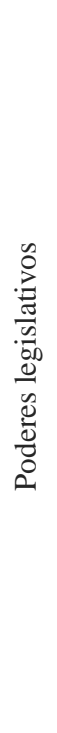 } & Veto total & $\begin{array}{l}3 \\
\text { Derrubada do veto total re- } \\
\text { quer maioria superior a } 2 / 3 \text { do } \\
\text { quórum }{ }^{17} \text {. }\end{array}$ & $\begin{array}{l}2 \\
\text { Derrubada do veto total requer } \\
\text { maioria de } 2 / 3 \text { do quórum. }\end{array}$ & $\begin{array}{l}2 \\
\text { Derrubada do veto total requer } \\
\text { maioria de } 2 / 3 \text { do quórum. }\end{array}$ \\
\hline & Veto parcial & $\begin{array}{l}3 \\
\text { Derrubada do veto parcial } \\
\text { requer maioria extraordinária. }\end{array}$ & $\begin{array}{l}3 \\
\text { Derrubada do veto parcial requer } \\
\text { maioria extraordinária. }\end{array}$ & $\begin{array}{l}3 \\
\text { Derrubada do veto parcial } \\
\text { requer maioria extraordinária. }\end{array}$ \\
\hline & Decreto & $\begin{array}{l}\text { 0 } \\
\text { Não há poder de decreto ou } \\
\text { só em casos de delegação } \\
\text { pela Assembleia. }\end{array}$ & $\begin{array}{l}0 \\
\text { Não há poder de decreto ou só } \\
\text { em casos de delegação pela } \\
\text { Assembleia. }\end{array}$ & $\begin{array}{l}1 \\
\text { Autoridade para expedir decre- } \\
\text { tos é limitada. }\end{array}$ \\
\hline & $\begin{array}{l}\text { Introdução exclusiva } \\
\text { de legislação }\end{array}$ & $\begin{array}{l}0 \\
\text { Sem poder exclusivo. }\end{array}$ & $\begin{array}{l}1 \\
\text { Possibilidade irrestrita de emen- } \\
\text { damento pela Assembleia. }\end{array}$ & $\begin{array}{l}1 \\
\text { Possibilidade irrestrita de } \\
\text { emendamento pela Assembleia. }\end{array}$ \\
\hline & $\begin{array}{l}\text { Poderes orçamentá- } \\
\text { rios }\end{array}$ & $\begin{array}{l}0 \\
\text { Autoridade irrestrita da As- } \\
\text { sembleia para preparar e/ou } \\
\text { emendar o orçamento. }\end{array}$ & $\begin{array}{l}4 \\
\text { Presidente prepara o orçamento, } \\
\text { sem possibilidade de emendas. }\end{array}$ & $\begin{array}{l}4 \\
\text { Presidente prepara o orçamen- } \\
\text { to, sem possibilidade de emen- } \\
\text { das. }\end{array}$ \\
\hline & Proposta de referendo & $\begin{array}{l}4 \\
\text { Possibilidade irrestrita }\end{array}$ & $\begin{array}{l}4 \\
\text { Possibilidade irrestrita }\end{array}$ & $\begin{array}{l}4 \\
\text { Possibilidade irrestrita }\end{array}$ \\
\hline \multirow{3}{*}{ 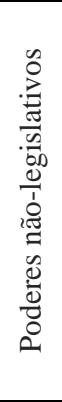 } & Formação de gabinete & $\begin{array}{l}4 \\
\text { Presidente nomeia o gabinete } \\
\text { sem necessidade de confir- } \\
\text { mação ou investidura. }\end{array}$ & $\begin{array}{l}4 \\
\text { Presidente nomeia o gabinete } \\
\text { sem necessidade de confirmação } \\
\text { ou investidura. }\end{array}$ & $\begin{array}{l}4 \\
\text { Presidente nomeia o gabinete } \\
\text { sem necessidade de confirma- } \\
\text { ção ou investidura. }\end{array}$ \\
\hline & $\begin{array}{l}\text { Destituição de gabi- } \\
\text { nete }\end{array}$ & $\begin{array}{l}4 \\
\text { Presidente destitui o gabinete } \\
\text { à sua vontade. }\end{array}$ & $\begin{array}{l}4 \\
\text { Presidente destitui o gabinete à } \\
\text { sua vontade. }\end{array}$ & $\begin{array}{l}4 \\
\text { Presidente destitui o gabinete à } \\
\text { sua vontade. }\end{array}$ \\
\hline & Censura & $\begin{array}{l}4 \\
\text { Assembleia não pode censu- } \\
\text { rar ou remover o gabinete ou } \\
\text { ministros. }\end{array}$ & $\begin{array}{l}4 \\
\text { Assembleia não pode censurar } \\
\text { ou remover o gabinete ou minis- } \\
\text { tros. }\end{array}$ & $\begin{array}{l}2 \\
\text { Assembleia pode censurar, mas } \\
\text { presidente pode responder } \\
\text { dissolvendo-a. }\end{array}$ \\
\hline
\end{tabular}

${ }^{15}$ Ver, por exemplo, Paz e Miño (2008); Ramírez Gallegos (2010); Santos (2010); Gargarella (2010).

${ }^{16}$ Ver, por exemplo, Acosta (2008) e Santos (2010).

${ }^{17}$ Para derrubada do veto, a Câmara poderia solicitar ao presidente a submissão do projeto a consulta popular. 


\begin{tabular}{|l|l|l|l|l|}
\hline $\begin{array}{l}\text { Dissolução da assem- } \\
\text { bleia }\end{array}$ & $\begin{array}{l}0 \\
\text { Sem previsão. }\end{array}$ & $\begin{array}{l}2 \\
\text { Sem previsão. } \\
\text { Requer nova eleição presiden- } \\
\text { cial. }\end{array}$ \\
\hline \multicolumn{2}{|l|}{ Índice Total } & 0,550 & 0,650 & 0,675 \\
\hline
\end{tabular}

* Índice elaborado por Shugart e Carey (1992).

Fonte: EQUADOR (1979; 1998; 2008). Elaboração do autor.

Para analisar a conformação dos poderes presidenciais nas constituições equatorianas, este trabalho utilizou o Índice de Poderes Presidenciais elaborado por Shugart e Carey (1992). A escolha desse indicador deve-se ao fato de ser uma medida classificada como adequada e válida pela literatura ${ }^{18}$, possuindo, ainda, uma boa cobertura dos países da América (e.g., FORTIN, 2013; DOYLE; ELGIE, 2015). Além disso, esse índice é baseado somente em poderes presidenciais expressos no texto constitucional, o que aumenta a confiabilidade da mensuração, uma vez que as constituições representam documentos publicamente disponíveis e não julgamentos contestáveis sobre o poder presidencial na prática (DOYLE; ELGIE, 2015).

O Índice é composto por dez indicadores ordinais, organizados em uma escala de zero a quatro, que podem ser classificados em dois diferentes grupos: Poderes legislativos e Poderes não-legislativos do presidente. Na primeira parte, estão os poderes de (1) Veto total; (2) Veto parcial; (3) Decreto; (4) Introdução exclusiva de legislação; (5) Poderes orçamentários; e (6) Proposta de referendo. Por sua vez, constituem poderes não-legislativos os de (7) Formação de gabinete; (8) Destituição de gabinete; (9) Censura; e (10) Dissolução da assembleia. Os critérios para pontuação em cada componente podem ser encontrados no Apêndice. $O$ valor final do índice é dado pela soma da pontuação obtida em todos os componentes, divida por seu valor máximo, isto é, 40 pontos, sendo padronizado na escola zero a um.

A análise dos índices calculados para as três últimas constituições equatorianas (1978, $1998,2008)$ revela um elevado poder do presidente para controlar o processo legislativo e uma alta capacidade institucional, que assegura ao Executivo uma maior força frente aos demais poderes republicanos. Por sua vez, nas constituições mais recentes, o desenho institucional estabelecido pela Carta Magna do país favorece ainda mais o Executivo no processo decisório, tendo em vista o incremento gradual de prerrogativas a favor do presidente a cada nova edição do texto constitucional, sejam elas legislativas ou não legislativas. Os resultados para o índice foram de 0,550, 0,650 e 0,675, respectivamente para as Constituições de 1978, 1998 e 2008.

A Constituição de 2008, classificada como pertencente ao paradigma do Novo Constitu-

\footnotetext{
${ }^{18}$ Fortin (2013) argumenta que qualquer medida de poder presidencial tem grande probabilidade de sofrer de problemas de validade. Contudo, entendemos que, no limite, esse problema pode ocorrer na mensuração de qualquer fenômeno social, sendo tarefa do pesquisador encontrar o máximo de validade e confiabilidade das medidas utilizadas. Ademais, a medida proposta por Doyle e Elgie (2015) nos parece interessante, não podendo ser utilizada neste estudo, no entanto, devido à ausência do cálculo do índice para a Constituição equatoriana de 2008. Por fim, justifica-se a não utilização do Índice de Poder Institucional Legislativo (IPIL), elaborado por García Montero (2009), tendo em vista a indisponibilidade dos regimentos internos da Assembleia Nacional do Equador para os períodos de interesse.
} 
cionalismo Latino-Americano, foi aquela que atribuiu maiores poderes ao presidente do Equador, mesmo tendo surgida apoiada em uma perspectiva inicialmente contrária à um sistema de concentração de poderes nas mãos do presidente. Entre as atribuições do Chefe da Função Executiva assinaladas pela Constituição, está a capacidade para expedir decretos com força de lei, sendo essa prerrogativa limitada a legislações em matéria econômica (artigo 140). Além disso, é atribuição exclusiva do presidente introduzir legislação que crie, modifique ou suprima impostos, aumentem o gasto público ou modifiquem a divisão político administrativa do país (artigo 135), bem como é o responsável por preparar a proposta inicial do orçamento nacional, sem possibilidade de emendas pelos assembleístas (artigos 147 e 148).

A Constituição de 2008 também outorga ao presidente as capacidades de vetar total ou parcialmente os projetos aprovados pela Assembleia Nacional, sendo necessários os votos de dois terços e maioria extraordinária, respectivamente, para derrubada do veto presidencial (artigo 138), além de poder convocar irrestritamente referendo, para consulta à população (artigo 104). Já em relação aos poderes não-legislativos, o Chefe da Função Executiva equatoriana possui enormes liberdades para formar e destituir o gabinete, não necessitando da confirmação ou investidura dos ministros de Estado pelos parlamentares (artigo 179, inciso 9).

Contudo, uma das mais significativas mudanças introduzidas pela nova Constituição equatoriana de 2008 em comparação às cartas anteriores é a possibilidade de destituição conjunta da presidência e da Assembleia Nacional, conforme expresso em seus artigos 130, 131 e 148. Por um lado, esse dispositivo pode aumentar o poder da Função Legislativa, que pode aplicar a censura ao presidente em casos de "crise política". Entretanto, esse mecanismo reforça os poderes presidenciais, já que permite ao Chefe do Executivo ameaçar os legisladores diante de impasses políticos e, dessa forma, facilitar a preponderância de suas preferências frente as dos demais atores políticos do país.

Quadro 2. Poderes presidenciais e poderes partidarios na América Latina

\begin{tabular}{|l|l|l|}
\hline Poderes constitucionais vs. Poderes partidários & Minoria legislativa & Maioria legislativa \\
\hline Baixa influência legislativa do presidente & Brasil 46, Chile 25, Bolívia 2002, Equador 1979 & $\begin{array}{l}\text { El Salvador, Uruguai, } \\
\text { Costa Rica, Paraguai 91, } \\
\text { Venezuela 99, México }\end{array}$ \\
\hline Forte influência legislativa do presidente & $\begin{array}{l}\text { Chile 89, Colômbia 68, Brasil 88, Colômbia 91, } \\
\text { Peru 91, Equador 1998 }\end{array}$ & $\begin{array}{l}\text { Argentina 1994; Venezu- } \\
\text { ela 1999, Equador 2008 }\end{array}$ \\
\hline
\end{tabular}

Fonte: Basabe-Serrano, Pachano e Mejia Acosta (2010).

Se por um lado, a nova Constituição do Equador de 2008 não só reforça, como aumenta os poderes formalmente atribuídos ao presidente, deve-se levar em conta, ainda, um incremento do apoio presidencial pelos parlamentares do partido oficialista na Assembleia Nacional, aumentando ainda mais o seu predomínio frente às demais funções do Estado. Conforme demonstra o quadro acima, os sucessivos aumentos dos poderes presidenciais foram acompanhados de um aumento em seus poderes partidários, passando, em 2008, a atuar com maioria no parlamento, diferentemente do que aconteceu nos demais países, 
em que a ampliação dos poderes do Executivo buscou compensar a ausência de respaldo político do governo na arena legislativa (BASABE-SERRANO; PACHANO; MEJIA ACOSTA, 2010).

Quadro 3: Duração de coalizões e desempenho legislativo antes e depois das reformas constitucionais no Equador (1979-1995 e 1996-2006)

\begin{tabular}{|l|l|l|l|}
\hline Período & $1979-1995$ & $1996-2006$ & Total/Média \\
\hline $\begin{array}{l}\text { Proporção de projetos ordinários (e de urgência) iniciados } \\
\text { pelo Executivo }\end{array}$ & $0,35(0,68)$ & $0,38(0,64)$ & $0,36(0,66)$ \\
\hline Projetos ordinários (e de urgência) iniciados a cada ano & $9,3(3,2)$ & $6,3(5,9)$ & $12,6(12,3)$ \\
\hline Média de duração da coalização (meses) & 19,2 & 12 & 15,6 \\
\hline Taxa de renovação dos gabinetes ${ }^{\text {a }}$ & 0,52 & 0,58 & 0,54 \\
\hline Taxa de mudança de partidos ${ }^{\text {t }}$ & 0,12 & 0,09 & 0,11 \\
\hline
\end{tabular}

Notas:

a) Datos de remoción de gabinetes disponibles hasta el año 2003.

b) Datos de cambio de partidos disponibles hasta el año 2002.

Fonte: Mejía Acosta y Polga Hecimovich, 2009.

Essa nova conformação política do país tem trazido duas consequências principais: o maior sucesso legislativo do presidente e a maior estabilidade política. Os dados apresentados acima indicam que, em que pese as alterações realizadas na Carta Magna equatoriana de 1998, "las modificaciones institucionales no lograron fortalecer la posición del presidente y tampoco erradicar los mecanismos informales que facilitaban la cooperación entre Ejecutivo y Legislativo en el período anterior" (BASABE-SERRANO; PACHANO; MEJIA ACOSTA, 2010). Nos anos em que esteve vigente a carta promulgada em 1998, assistiu-se a uma maioria volatilidade dos membros do gabinete e a uma baixa variação no número e proporção de projetos do Executivo aprovados pelo parlamento.

Por sua vez, a eleição de Rafael Correa, em 2006, marcou o início de uma nova realidade partidária no país, com um processo de deslegitimação dos atores e partidos políticos tradicionais. "Así, el surgimiento de la "revolución ciudadana" refleja el colapso tanto del modelo político propuesto por la Constitución de 1978 como de las fallidas reformas establecidas en la de 1998" (BASABE-SERRANO; PACHANO; MEJIA ACOSTA, 2010). Conforme argumenta Polga-Hecimovich (2013), o sistema partidário equatoriano tem se aproximado ao modelo de países vizinhos, como o do Peru e da Bolívia, em que os movimentos políticos de mais curta trajetória têm substituído os partidos tradicionais. Somado a isso, o autor ainda menciona uma sistemática imposição de limites ao crescimento de partidos de oposição a Rafael Correa, por meio das regras de registro eleitoral. Nesse cenário, a obtenção de maiorias legislativas deixou de ser um problema para o presidente equatoriano, como ocorria antes da chegada de Correa. Essa realidade de maiorias oficialistas é ainda mais marcante a partir de 2013, quando foi possível perceber uma alta disciplina dos legisladores do Alianza País (MEJÍA ACOSTA, 2009; FREIDENBERG, 2012; BASABE-SERRANO; JULIÁN MARTÍNEZ, 2014).

Atualmente, o Presidente Rafael Correa conta com o apoio de, aproximadamente, três quartos dos assembleístas. Como se vê no Quadro 4, abaixo, o sucesso do presidente na aprovação de projetos de lei é bastante significativo, com uma taxa de sucesso de $61,2 \%$, isto é, dos 67 projetos de lei apresentados por ele no período, 41 foram incluídos no Regis- 
tro Oficial, passando a valer de forma efetiva. Por outro lado, a taxa de aprovação dos projetos originados da própria Assembleia é de apenas 11,6\%. No ano de 2012, essa diferença é ainda mais marcante. Dos seis projetos apresentados por Rafael Correa, somente um não foi aprovado. Enquanto isso, os assembleístas apresentaram 119 projetos de leis, dos quais somente um foi aprovado. De forma adicional, o presidente equatoriano tem utilizado o instituto do decreto para legislar com ainda mais força. Somente em 2012, foram promulgados 400 decretos, dos quais 124 tratavam-se de políticas de Estado.

Cabe lembrar ademais que, além de uma análise quantitativa, o presidente equatoriano tem conseguido implementar agendas políticas importantes, que tem promovido grandes alterações nas leis e no contexto do país. Nesse sentido, Rafael Correia logrou sucesso na elaboração da Lei de Águas e na reforma da Lei de Educação Intercultural, em 2010, que coloram em risco os direitos dos povos indígenas - participantes chave do processo de reforma constitucional - e os princípios fundamentais da plurinacionalidade, bem como no Referendum Constitucional e na Consulta Popular de 2011 e a Reforma Constitucional de 2015, que destacam a relação de sobreposição e conflito do presidente com as demais funções do Estado

Para Polga-Hecimovich (2013, p. 152), "en el escenario actual, el Presidente impone su voluntad sobre todas las facetas de la política ecuatoriana, además del peso que ejerce sobre la rama judicial". Somado à alta popularidade que alcança o presidente junto à população equatoriana, Correa combina uma grande legitimidade, fortes poderes institucionais e características de lideranças populistas, que lhe tem permitido ir além da separação de poderes e exercer um extenso controle sobre a política nacional.

Quadro 4. Projetos de Lei segundo seu estado de trâmite na Assembleia Nacional do Equador (2009 a 2013)

\begin{tabular}{|c|c|c|c|c|c|c|c|c|c|c|}
\hline Ano & Proponente & $\begin{array}{l}\text { Projetos } \\
\text { apresen- } \\
\text { tados }\end{array}$ & $\begin{array}{l}\text { Qualifi- } \\
\text { cação da } \\
\text { CAL }\end{array}$ & $\begin{array}{l}\text { Primeiro } \\
\text { debate }\end{array}$ & $\begin{array}{l}\text { Segun- } \\
\text { do } \\
\text { debate }\end{array}$ & \begin{tabular}{|l|} 
Aprova- \\
ção do \\
plenário
\end{tabular} & $\begin{array}{l}\text { Veto } \\
\text { parcial }\end{array}$ & $\begin{array}{l}\text { Veto } \\
\text { total }\end{array}$ & $\begin{array}{l}\text { Texto } \\
\text { definiti- } \\
\text { vo }\end{array}$ & $\begin{array}{l}\text { Regis- } \\
\text { tro } \\
\text { Oficial }\end{array}$ \\
\hline \multirow{6}{*}{2009} & Assembleístas & 74 & 60 & 52 & 47 & 39 & 24 & 3 & 35 & 26 \\
\hline & Cidadania & 2 & 1 & 1 & 1 & 1 & 1 & 0 & 1 & 1 \\
\hline & $\begin{array}{l}\text { Função de Transparência e } \\
\text { Controle Social }\end{array}$ & 2 & 1 & 1 & 1 & 1 & 1 & 0 & 1 & 1 \\
\hline & Função Judicial & 2 & 1 & 1 & 1 & 1 & 1 & 0 & 1 & 0 \\
\hline & Presidente da República & 18 & 18 & 18 & 18 & 15 & 12 & 0 & 13 & 13 \\
\hline & Total & 98 & 81 & 73 & 68 & 57 & 39 & 3 & 51 & 41 \\
\hline \multirow{6}{*}{2010} & Assembleístas & 142 & 117 & 82 & 51 & 21 & 4 & 14 & 14 & 16 \\
\hline & Cidadania & 1 & 0 & 0 & 0 & 0 & 0 & 0 & 0 & 0 \\
\hline & $\begin{array}{l}\text { Função de Transparência e } \\
\text { Controle Social }\end{array}$ & 3 & 2 & 2 & 2 & 2 & 2 & 0 & 1 & 1 \\
\hline & Função Judicial & 2 & 2 & 1 & 1 & 1 & 0 & 1 & 0 & 0 \\
\hline & Presidente da República & 15 & 14 & 13 & 11 & 8 & 5 & 0 & 8 & 10 \\
\hline & Total & 163 & 135 & 98 & 65 & 32 & 11 & 15 & 23 & 27 \\
\hline \multirow{5}{*}{2011} & Assembleístas & 120 & 104 & 61 & 37 & 13 & 7 & 2 & 4 & 11 \\
\hline & \begin{tabular}{|l} 
Função de Transparência e \\
Controle Social
\end{tabular} & 1 & 1 & 1 & 1 & 1 & 1 & 0 & 1 & 1 \\
\hline & Função Eleitoral & 1 & 1 & 1 & 1 & 1 & 1 & 0 & 0 & 1 \\
\hline & Presidente da República & 19 & 18 & 15 & 12 & 10 & 3 & 0 & 7 & 11 \\
\hline & Total & 141 & 124 & 78 & 51 & 25 & 12 & 2 & 12 & 24 \\
\hline \multirow{2}{*}{2012} & Assembleístas & 119 & 84 & 56 & 19 & 1 & 1 & 0 & 1 & 1 \\
\hline & Cidadania & 3 & 2 & 0 & 0 & 0 & 0 & 0 & 0 & 0 \\
\hline
\end{tabular}




\begin{tabular}{|c|c|c|c|c|c|c|c|c|c|c|}
\hline & Função Judicial & 1 & 1 & 1 & 1 & 1 & 1 & 0 & 1 & 1 \\
\hline & Presidente da República & 6 & 6 & 6 & 5 & 5 & 3 & 0 & 3 & 5 \\
\hline & Total & 129 & 93 & 63 & 25 & 7 & 5 & 0 & 5 & 7 \\
\hline \multirow{4}{*}{2013} & Assembleístas & 21 & 9 & 3 & 2 & 1 & 0 & 0 & 1 & 1 \\
\hline & Cidadania & 1 & 0 & 0 & 0 & 0 & 0 & 0 & 0 & 0 \\
\hline & Presidente da República & 9 & 8 & 8 & 7 & 2 & 1 & 0 & 2 & 2 \\
\hline & Total & 31 & 17 & 11 & 9 & 3 & 1 & 0 & 3 & 3 \\
\hline \multirow{7}{*}{$\begin{array}{l}\text { TOTAL } \\
(2009- \\
2013)\end{array}$} & Assembleístas & 476 & 374 & 254 & 156 & 75 & 36 & 19 & 55 & 55 \\
\hline & Cidadania & 476 & 3 & 1 & 1 & 1 & 1 & 0 & 1 & 1 \\
\hline & $\begin{array}{l}\text { Função de Transparência e } \\
\text { Controle Social }\end{array}$ & 6 & 4 & 4 & 4 & 4 & 4 & 0 & 3 & 3 \\
\hline & Função Eleitoral & 1 & 1 & 1 & 1 & 1 & 1 & 0 & 0 & 1 \\
\hline & Função Judicial & 5 & 4 & 3 & 3 & 3 & 2 & 1 & 2 & 1 \\
\hline & Presidente da República & 67 & 64 & 60 & 53 & 40 & 24 & 0 & 33 & 41 \\
\hline & Total & 562 & 450 & 323 & 218 & 124 & 68 & 20 & 94 & 102 \\
\hline
\end{tabular}

* Consejo de Administración Legislativa (CAL).

Fuente: Site da Assembleia Nacional do Equador - Trâmite das Leis. Elaboração do Autor.

\section{CONSIDERAÇÕES FINAIS}

Diversos teóricos têm argumentado sobre a incidência histórica do hiperpresidencialismo na América Latina. O termo "hiperpresidencialismo" é utilizado aqui para designar um desenho constitucional caracterizado pela concentração de poderes nas mãos do chefe do Executivo, em desfavor do equilíbrio entre as funções do Estado ${ }^{19}$. Gargarella (2010), por exemplo, argumenta que a existência de legisladores constituintes com pouca vocação ou enormes dificuldades para ingressar na "sala de máquinas" da Constituição tem sido um paradigma comum em toda a América Latina. Sala de máquinas é a metáfora utilizada pelo autor para referir-se à seção orgânica do texto constitucional, a qual define a estrutura e a organização do poder político.

Entretanto, presidentes com poderes fortes, racionalmente, tendem a não aceitar recortes sobre o seu próprio poder. Tal situação tem sido percebida no Equador, onde se verifica um forte acirramento entre a posição dos movimentos e organizações sociais, notadamente aqueles que reúnem os povos indígenas, e as ações governamentais de Rafael Correa. Para a participação popular, esse contexto demarca o risco de se confiar em líderes messiânicos e carismáticos, diante da história autoritária da América Latina, podendo romper com as bases do Constitucionalismo "democrático". Alguns autores chegam, inclusive, a identificar o governo equatoriano como um "autoritarismo competitivo" (LEVITSKY; WAY, 2002), que implica um permanente desrespeito às instituições políticas formais, à separação dos poderes do Estado e aos direitos políticos e sociais da população. A presença de presidentes hiperpoderosos não compõe o núcleo de qualquer democracia que busque ser participativa, reverberando em uma líder que menospreza o pluralismo e a participação política.

Ademais, o estilo presidencial de Correa tem caracterizado o seu governo como parte dos populismos de esquerda latino-americanos (DE LA TORRE; PERUZZOTTI, 2008; LEVITSKY; ROBERTS, 2011; FREIDENBERG, 2012). Sob esse conceito, encontram-se os gover-

\footnotetext{
${ }^{19}$ Esse conceito pode ser encontrado em Nino (1992) e O'Donnell (1991).
} 
nos cuja legitimidade está baseada não no respeito às instituições, mas na mobilização política, gerando posições e identidades fortes, que dividem a sociedade entre o povo, encarnado na figura do líder político, de um lado, e uma imagem construída dos inimigos da pátria, do outro (DE LA TORRE; PERUZZOTTI, 2008). Atualmente, verifica-se que, no Equador, os espaços para o dissenso são cada vez menores. "La ausencia de controles desde las instituciones de representación política y la situación de dependencia y sumisión del Poder Judicial viabilizan dicha forma de hacer política en el país" (BASABE-SERRANO; MARTíNEZ, 2014 , p. 146). Nesse mesmo sentido, Freidenberg (2011) verificou a intensificação do processo de cooptação institucional dos poderes estatais pela Função Executiva, outorgando um forte poder ao Presidente com a construção de projeto de corte hegemónico, personalista e centralizador por parte de Rafael Correa.

A institucionalidade de um sistema político que não se constrói sobre o princípio da autonomia e do equilíbrio entre as funções do Estado pode debilitar sua própria institucionalidade democrática. Quando o Presidente dispõe de uma posição privilegiada frente às demais funções do Estado, possuindo o controle de ferramentas institucionais para colocar em prática suas vontades, cria-se as condições para o abuso da Função Executiva, debilitando a autoridade legislativa e tornando a Função Judiciária um poder institucionalmente frágil. Essa mesma dinâmica pode acabar por tornar inócua a transformação constitucional promovida no Equador nos últimos anos, na medida em que a Função Executiva encontrase em condições de vetar ou impor sérios limites às iniciativas de participação política por parte da população, colocando os movimentos sociais em uma posição dúbia de confrontação ou cooperação com o governo.

\section{REFERÊNCIAS}

ACOSTA, A. El Buen Vivir: una oportunidad para construir. Ecuador debate, 75, Quito. 2008.

ALTMAN, David. The politics of coalition formation and survival in multiparty presidential democracies: The case of Uruguay, 1989-1999. Party Politics, Ano 3, Volume 6, 2000. AMORIM NETO, O.; COX, Gary; MCCUBBINS, Mathew. Agenda Power in Brazil's Câmara dos Deputados, 1989-98. World Politics (Print), Princeton University, v. 55, n.4, p. 550-578, 2003.

AMORIM NETO, Octavio. Gabinetes presidenciais, ciclos eleitorais e disciplina legislativa no Brasil. Revista Dados, Rio de Janeiro, v. 43, n. 2, pp. 479-519, 2000.

BASABE-SERRANO, Santiago; PACHANO, Simón; MEJIA ACOSTA, Andrés. La democracia inconclusa: Derechos fundamentales, instituciones políticas y rendimientos gubernamentales en Ecuador (1979-2008). Rev. cienc. polít. (Santiago), Santiago, v. 30, n. 1, p. 65-85, 2010.

BASABE-SERRANO, Santiago; MARTINEZ, Julián. Ecuador: cada vez menos democracia, cada vez más autoritarismo... con elecciones. Rev. cienc. polít. (Santiago), Santiago, v. 34, n. 1, p. 145-170, 2014.

BRANDÃO, P. O Novo Constitucionalismo Pluralista Latino-Americano. Rio de Janeiro: Lu- 
men Juris. 2015.

CAREY, John. Presidentialism 25 Years After Linz. 2014. Disponível em: http://users.ox.ac. uk/ latc0045/CPP/News_\&_Events_files/Carey\%20-

\%200xford\%20Keynote\%20Abridged\%20for\%20Elgie\%20Blog\%20-\%20July\%202014.pdf

CHAISTY, Paul; CHEESEMAN, Nic; POWER; Timothy. Rethinking the 'presidentialism debate': conceptualizing coalitional politics in cross-regional perspective. Democratization, Vol. 21, No. 1, p. 72-94, 2014.

CHEIBUB, J.; LIMONGI, F. Modes of Government Formation and the Survival of Democratic Regimes: Presidentialism and Parliamentarism Reconsidered. Annual Review of Political Science5, p. 151-179. 2002.

COlOMER, J. M.; NEGRETTO, G. L. Can Presidentialism Work Like Parliamentarism? Government and Opposition, 40: 60-89, 2005.

COX, Gary W.; McCUBBINS, Mathew D. Setting the Agenda: Responsible Party Government in the U.S. House of Representatives. 2005.

COX, Gary W.; MORGENSTERN, Scott. Epilogue: Latin Americas reactive assemblies and proactive presidents. In: MORGENSTERN, Scott; NACIF, Benito (orgs.), Legislative politics in Latin America. Cambridge: Cambridge University Press, 2002.

DE LA TORRE, Carlos de la; PERUZZOTTI, Enrique. El retorno del pueblo Populismo y nuevas democracias en América Latina. Quito, Ecuador, Flaco, 2008.

DIERMEIER, Daniel; VLAICU, Razvan, Executive Control and Legislative Success. Novembro, 2009. Disponível em: http://ssrn.com/abstract=1118163.

DOYLE, David; ELGIE, Robert. Maximizing the reliability of cross-national measures of presidential power. British Journal of Political Science, 2015.

ECUADOR. Constitución Política de Ecuador. Quito, 15 de enero de 1978.

ECUADOR. Constitución de Ecuador. Riobamba, 5 de junio de 1998.

ECUADOR. Constitución de la Republica del Ecuador. Tribunal Constitucional. Quito, Octubre del 2008.

ECHEVERRÍA, J. Los paradigmas del presidencialismo en el Ecuador. La Tendencia, TRAMASOCIAL, vol. 5. 2005.

FIGUEIREDO, Argelina. O Executivo nos sistemas de governo democrático. Bib, no. 58, pp. 7- 28, 2008.

FIGUEIREDO, Argelina; LIMONGI, Fernando. Executivo e legislativo na nova ordem constitucional. Rio de Janeiro: Editora FGV, 1999.

FORTIN, Jessica. Measuring presidential powers: Some pitfalls of aggregate measurement. International Political Science Review, 34(1), p. 91-112, 2013.

FREIDENBERG, Flavia. Ecuador 2011: Revolución Ciudadana, estabilidad presidencial y personalismo político. Rev. cienc. polít. (Santiago), Santiago, v. 32, n. 1, p. 129-150, 2012.

GARGARELLA, R. 200 años de constitucionalismo en América Latina (1810-2010). Universidad de Buenos Aires, Buenos Aires. 2010.

GARAVITO, César Rodríguez (coord.). El derecho en América Latina: un mapa para el pensamiento jurídico del siglo XXI. 1a ed. - Buenos Aires: Siglo Veintiuno Editores, 2011.

GARCÍA MONTERO, Mercedes (2009) Presidentes y parlamentos: ¿Quién controla la activi- 
dad legislativa en América Latina? Centro de Investigaciones Sociológicas - CIS. Madrid, 2009.

INACIO, M; LLANOS, M. The Institutional Presidency in Latin America: A Comparative Analysis. Presented to the 2014 APSA Annual Meeting of the American Political Science Association, Washington DC, August 28-31, 2014.

JENKINS, Jeffrey A.; MONROE, Nathan W. Buying Negative Agenda Control in the U.S. House. American Journal of Political Science 56: 897-912, 2012.

LEVITSKY, Steve; WAY, Lucan. Elections without Democracy. The Rise of Competitive Authoritarianism. Journal of Democracy 13 (2): 51-65. 2002.

LEVISTKY, Steve; ROBERTS, Kennet. Introduction: Latin America's 'Left Turn': A Framework for Analysis. In: LEVISTKY, Steve; ROBERTS, Kennet (Eds.). The Resurgence of the Latin American Left. Maryland: The John Hopkins University Press (2011).

LIJPHART, Arend. Modelos de Democracia: desempenho e padrões de governo em 36 países. Tradução de Roberto Franco. 2a Ed. Rio de Janeiro: Civilização Brasileira, 2008.

LINZ, Juan. Presidential or parliamentary democracy: does it make a difference? In: LINZ, Juan; VALENZUELA, Arturo (eds.), The failure of presidential democracy, comparative perspectives, vol. I, Baltimore, Johns Hopkins University Press, 1994.

LINZ, J.; VALENZUELA, A. The Failure of Presidential Democracy. Baltimore: The John Hopkins University Press. 1994.

LINZÁN, Luis Fernando Ávila; FRANCO, Alex Valle. ¿El derecho de la miseria o la miseria del derecho? In: Emancipación y transformación constitucional. Serie Crítica Y Derecho - № 1. Quito: Corte Constitucional para el Período de Transición, marzo de 2011.

MAGALHÃES, José Luiz Quadros de; WEIL, Henrique. Bioética no Estado de Direito Plurinacional. Revista Direitos Culturais, n. 8, v. 5, pp. 13-26, 2010.

MAINWARING, Scott; SHUGART, Matthew. Juan Linz, presidencialismo e democracia: uma avaliação crítica. Novos Estudos Cebrap, 37:191-213, 1993.

MARTINEZ GALLARDO, Cecilia. Out of the Cabinet: What Drives Defections from the Government in Presidential Systems? Comparative Political Studies, vol. 45, Issue1, January, pp. 62-90, 2012.

MEJÍA ACOSTA, Andrés; POLGA HECIMOVICH, John. Parlamentary Solutions to Presidential Crises to Ecuador. In: MARSTEINTREDET, L.; LLANOS, M. (edits.). Presidential Crises in Latin America. Palgrave: Basingstoke, 2009.

MOE, T. The Politics of Structural Choice: Toward a Theory of Public Bureaucracy. In: WILLIAMSON, O. E. Organization Theory: From Chester Barnard to the Present and Beyond. New York: Oxford University Press, 1990.

MOE, T.; CALDWELL, M. The Institutional Foundations of Democratic Government: A Comparison of Presidential and Parliamentary Systems. Journal of Institutional and Theoretical Economics 150/1: 171-195, 1994.

MOE, T. M.; HOWELL, W. G. The presidential power of unilateral action. Journal of Law, Economics, and Organization, Oxford Univ Press, v. 15, n. 1, p. 132-179, 1999.

NEGRETTO, Gabriel. Government Capacities and Policymaking by Decree in Latin America.' Comparative Political Studies 37 (5): 531-62, 2004. 
NEGRETTO, G. Paradojas de La reforma constitucional em América Latina. Journal of Democracy en Español. Volumen 1. 2009.

NEUSTADT, Richard E. Presidential Power and the Modern Presidents. New York: Free Press, 1960.

NINO, C. (Ed.). Presidencialismo vs. Parlamentarismo. Consejo para Consolidación de la Democracia, Buenos Aires. 1987.

O'DONNELL, Guillermo. Democracia Delegativa? Novos Estudos CEBRAP, São Paulo, 1991.

OYARTE MARTÍNEZ, R. Relaciones Ejecutivo-Legislativo. In: ANDRADE, S.; et al (Ed.). La nueva constitución del Ecuador. Quito, Universidad Andina Simón Bolivar. 2009.

PAZ y MIÑO, Juan. El ciclo del processo constituyente en Ecuador. In ACOSTA, Alberto. Entre el quiebre y la realidad. Constitución 2008. Quito: Abya Yala, 2008.

PEREIRA, Carlos; POWER, Timothy J.; RENNÓ, Lucio. Under What Conditions Do Presidents Resort to Decree Power? Journal of Politics 67 (1): 178-200, 2005.

POLGA-HECIMOVICH, John. Ecuador: estabilidad institucional y la consolidación de poder de Rafael Correa. Rev. cienc. polít. (Santiago), Santiago, v. 33, n. 1, p. 135-160, 2013.

RAILE, Eric; PEREIRA, C.; POWER, Timothy. The Executive Toolbox: Building Legislative Support in Multiparty Presidential Regime. Political Research Quarterly, v. 64, p. 323-334, 2011.

RAMÍREZ GALLEGOS, F. Desencuentros, convergencias y polarización (y viceversa). El gobierno ecuatoriano y los movimientos sociales. Nueva Sociedad, no 227. 2010.

ROHDE, D. W. Reflections on the Practice of Theorizing: Conditional Party Government in the Twenty- First Century, Journal of Politics, vol. 75, pp. 849-864, 2013.

SANTOS, B. S. Pensar el estado y la sociedad: Desafíos actuales. $1^{\mathrm{a}}$ ed. Buenos Aires: CLACSO Ediciones e Waldhuter Editores, 2009.

SANTOS, B. S. Refundación del Estado en América Latina: perspectivas desde una epistemologia del Sur. Instituto Internacional de Derecho y Sociedad. Lima, 2010.

SAIEGH, S. Political Prowess or Lady Luck? Evaluating Chief Executives' Legislative Success Rates. Journal of Politics, Vol 71, No.4: 1-15, 2009.

SHUGART, Matthew S.; CAREY, John M. Presidents and Assemblies: Constitutional Design and Electoral Dynamics. Cambridge: Cambridge University Press, 1992.

VICIANO PASTOR, R.; MARTÍNEZ DALMAU, R. Los procesos constituyentes latinoamericanos y el nuevo paradigma constitucional. Revista del Instituto de Ciencias Jurídicas de Puebla A.C., núm. 25, pp. 7-29, 2010.

VICIANO PASTOR, R.; MARTÍNEZ DALMAU, R. El Nuevo Constitucionalismo Latinoamericano: fundamentos para una construcción doctrinal. Revista General de Derecho Público Comparado, no 9, 2011. 